\title{
EVARISTO DE MORAES FILHO E A MAIORIDADE DOS TRABALHADORES BRASILEIROS
}

\section{Glaucia Villas Bôas}

No acervo das pesquisas sociológicas, o lugar ocupado pelo livro O problema do sindicato único no Brasil e seus fundamentos sociológicos (1 ed. 1952), de Evaristo de Moraes Filho, merece ser revisto. O autor faz a defesa impecável da adoção de uma abordagem sociológica no estudo das associações profissionais e dos sindicatos operários, reunindo uma disciplina e um tema que até então não tinham sido relacionados, mas cuja validade poderia ter sido reconhecida em pequeno círculo de estudiosos da sociologia e intelectuais voltados para a institucionalização da disciplina naquela época. No campo do direito, as dificuldades para o reconhecimento de suas teses não eram menores, embora os motivos não fossem os mesmos. O reconhecimento da importância de uma sociologia do direito enfrentava as hostilidades dos juristas, mais

Artigo recebido em setembro/2003

Aprovado em março/2004 afeitos às matérias normativo-doutrinárias próprias do seu métier, legitimado pela longa tradição de trabalho, do que às concepções e às práticas sociológicas que não só guardavam o caráter de "novidade" como também almejavam à neutralidade axiológica. O pioneirismo de Evaristo de Moraes Filho não se limita, porém, ao uso de abordagem sociológica para a compreensão do surgimento e do papel das primeiras associações sindicais no Brasil, nem tampouco à posição que adotou em relação à explicação sociológica do fato jurídico, encontra-se, antes, a meu ver, no significado que atribui à capacidade de associação livre por interesse (Weber, 1991, pp. 25-30) dos trabalhadores para a construção da sociedade moderna no país. Ao reconhecer a maioridade dos trabalhadores brasileiros para lutar pela melhoria de suas condições de vida, Evaristo toma posição contrária a um dos mais eficazes mitos da cultura brasileira - ambigüidade e incapacidade de os brasileiros se tornarem 
"modernos" -, para o que haveriam de recorrer a verdadeiro Leviatã. É defendendo o ponto de vista de que a obra Oproblema do sindicato único no Brasil e seus fundamentos sociológicos remou contra a maré do seu tempo, e, ainda, se põe hoje contra as interpretações da "faltosa" e "incompleta" sociedade brasileira que procuro aqui rever $\mathrm{o}$ pensamento de seu autor no quadro das interpretações sobre a modernidade no Brasil.

Insolidarismo social é a expressão que define a "falta" ou a "ausência" de instituições organizadas livremente para atender a interesses de grupos, e cuja durabilidade é essencial para que sejam reconhecidas e se tornem eficazes. A fugacidade das instituições no Brasil, como uma característica da cultura brasileira, tornara-se questão relevante no pensamento de Oliveira Vianna, mas, segundo Evaristo, dela tinham se ocupado também Gilberto Freyre, Capistrano de Abreu, Sérgio Buarque de Holanda, Alberto Torres e Tobias Barreto (Moraes Filho, 1978, pp. 314-319). O insolidarismo devia ser combatido programaticamente, evitando-se a fragmentação e o afrouxamento dos laços de instituições e associações. Diferenciando-se porém de seus interlocutores, Evaristo escreve um livro em que as associações operárias e sindicais adquirem centralidade na pesquisa e reflexão do autor, levando-o a argumentar que a pressão política que exerceram, em finais do século XIX e primeiras décadas do século XX, foi indispensável para a formulação das leis trabalhistas no país. Com tal argumento, $O$ problema do sindicato único no Brasil desmistificava a crença na "outorga" das leis aos trabalhadores pelo governo autoritário de Getúlio Vargas.

Tanto uma como outra das duas questões apontadas - a abordagem sociológica das associações operárias e sindicais, e a relação entre capacidade de associação livre por interesse e a construção de uma sociedade moderna - levam aqui à nova interpretação da obra em pauta, cuja tarefa é conferir às idéias de Evaristo de Moraes Filho o seu "devido lugar" no campo do pensamento social brasileiro e na história da sociologia, particularmente no Rio de Janeiro. Acredito que aquelas questões ficaram obscurecidas nas revisões e nas interpretações do pensamento sociológico por dois motivos. Primeiro, pelo fato de que o livro se tornou conhecido pela tese contrária à política do Estado Novo levada a cabo por Getúlio Vargas. A interpretação corrente é de que seu autor defende as associações, as reivindicações e as lutas operárias como força de pressão para a promulgação de decretos e leis dos anos de 1930, ${ }^{1}$ reunidos na Consolidação das Leis do Trabalho, que entrou em vigor em 1943 durante o Estado Novo. Combatendo desta forma a ideologia e a historiografia oficiais que atribuem a Getúlio Vargas a outorga das leis, o livro, publicado em 1952, no Rio de Janeiro, pela editora A Noite, foi visto como manual jurídico "quase de prática forense" (Moraes Filho, 1978), muito embora se tratasse de fato de um libelo contra a política trabalhista do Estado Novo. Em escritos e entrevistas, o autor confirma a versão da recepção tardia do livro no campo da sociologia. Ao rememorar os efeitos de seu trabalho, Evaristo não esconde sua insatisfação com o "esquecimento" do livro nas bibliografias das pesquisas sobre o sindicalismo no Brasil (Idem, pp. 327-328). ${ }^{2}$

Há que se reconhecer que não é de pouca monta o motivo que supostamente marcou a recepção de O problema do sindicato único no Brasil tanto no campo do direito como no da sociologia. O fato de seu autor retirar a classe operária de sua menoridade, atestando sua capacidade plena de lutar pelos seus direitos de forma organizada e contínua, por meio de pesquisa minuciosa que põe em relação movimentos, reivindicações, greves e legislação, durante a primeira república, questiona frontalmente o mito Vargas, guardião do outorgante das leis trabalhistas e do Estado como organizador das classes trabalhadoras. Contrapor-se a um mito que opera com símbolos e valores na construção de uma imagem passiva e dócil da classe trabalhadora não foi certamente tarefa fácil em um país afeito a práticas hierárquicas e autoritárias. $\mathrm{Pu}$ blicado no momento em que Getúlio Vargas retornava à presidência da República, o livro teve sua primeira edição esgotada. Mas o sucesso do lançamento não correspondeu à sua efetiva recepção nos meios intelectuais, sobretudo nos jurídico e sociológico. Ao contrário, guardou-se um longo silêncio sobre o escrito de Evaristo de Moraes Filho e, somente em 1978 - 26 anos depois da primeira 
edição -, é publicada a segunda edição pela editora Alfa Omega, em São Paulo, prefaciada por Paulo Sérgio Pinheiro.

Há, contudo, outro motivo tão ou mais importante do que o primeiro, embora ainda pouco explorado. Diz respeito ao instrumental sociológico utilizado pelo autor, sem o qual, a meu ver, dificilmente teria chegado ao questionamento do "mito da outorga". Ressalte-se que não se trata dos fundamentos sociológicos do livro, que já mencionei, porém da moldura conceitual proveniente da concepção de sociedade e história, que informam a constituição da pesquisa realizada por Evaristo. Tal moldura não corresponde e muito menos se confunde com os quadros teóricos e conceituais que marcaram definitivamente a sociologia dos anos de 1950. Explico melhor. Evaristo não faz uso das concepções teóricas inscritas na sociologia emergente da época que, referidas à mudança social, se fundam na comparação entre relações sociais tradicionais e relações sociais modernas, entre o velho e o novo, o desenvolvimento e o atraso do país. Ao contrário de tantos contemporâneos seus, não desqualifica o passado, mas, volta a ele para evidenciar o conjunto de ações, movimentos, greves e paralisações, cujo desenrolar provocou mudanças efetivas nos direitos dos trabalhadores. Além disso, a abordagem dos sindicatos e das associações operárias como grupos profissionais que agem e interagem e, portanto, fazem sociedade na acepção da sociologia de Simmel (Vergesellschaftung) livrou o sociólogo da medida de avaliação da sociedade brasileira, largamente utilizada na época, dada pelos pares conceituais status/contractus Gemeindschaft/Gesellschaft, cultura folk/civilização, que dividiam a sociedade em duas metades.

Não fosse a concepção de que "sociedade" se faz de um conjunto de ações e relações sociais, conflituosas e consensuais, adotada pelo autor, Evaristo de Moraes Filho dificilmente consideraria positivo e exitoso o movimento dos trabalhadores. No pósfácio à segunda edição do livro, afirma que fizera uso exagerado da idéia de grupo social como objeto da sociologia, quando deveria ter analisado os grupos sindicais dentro da problemática da sociedade global. Creio que, se essa "pro- blemática" concernisse aos problemas contidos nas noções de tradição e modernidade ou atraso e desenvolvimento, o autor não teria reconhecido a capacidade da classe trabalhadora e questionado o mito da outorga.

Por todas essas questões, que dizem respeito às peculiaridades do pensamento sociológico sobre a modernidade no Brasil, interessa percorrer a argumentação central do livro de Evaristo Moraes Filho, o qual possibilitou a revisão dos movimentos operários como força atuante na formulação da legislação, restituindo aos trabalhadores sua maioridade. Somente a "maioridade" (Kant, 1985) da classe trabalhadora asseguraria a associação livre por interesse que constitui um dos fundamentos da sociedade moderna. Se concordarmos com essa perspectiva, veremos como Evaristo de Moraes Filho discute a construção de uma sociedade moderna no Brasil, dialogando com intelectuais do seu tempo sobre problemas que dizem respeito ao que hoje se chama de "associativismo" ou capacidade de associação, sem que tenha feito uso da moldura teórica e conceitual que cunhou a sociologia dos anos de 1950, voltada para as mudanças sociais e históricas, o desenvolvimento e a modernização do país.

\section{A maioridade da classe trabalhadora}

A literatura sociológica dos anos de 1940 e 1950 está repleta de histórias, observações, descrições e séries estatísticas que evidenciam desigualdades, injustiças, abuso dos poderosos, desamparo dos despossuídos, preconceito e ausência de lei. Se o esquecimento mais do que a penúria é a maldição da pobreza (Arendt, 1988, p. 53), podese argumentar que as pesquisas sociológicas daquela época tiraram da obscuridade os pobres, trazendo, definitivamente, para a cena social e histórica, posseiros, ribeirinhos, migrantes e imigrantes, pau de arara, operários, despossuídos de toda sorte. Nesta importante vertente da sociologia brasileira, que desloca o foco da atenção das elites políticas e do "exotismo" dos grupos étnicos para destacar o "homem comum" das camadas sociais pobres e subordinadas da população, reside 
um paradoxo que consiste na recusa em reconhecer a "maioridade" 3 daqueles agentes sociais que põe em cena. Trabalhadores, operários pobres, cortadores de cana e pequenos proprietários rurais, balconistas, pescadores, indivíduos e grupos de baixa renda estariam de tal forma moldados à obediência dos poderosos, que não poderiam mais se desvencilhar do jugo ao qual estavam sujeitos. Muitas pesquisas concluíram pela incapacidade desses indivíduos e grupos de tomar decisões adequadas, reivindicar interesses, movimentar-se, reunir-se em associações com a finalidade de mudar sua situação de vida. Motivos dos mais variados serviram para o entendimento da inércia dos mais humildes, aterrados na labuta diária. O voto de cabresto (Leal, 1948), a ausência de um projeto para o futuro (Willems, 1952; Costa Pinto, 1997), a aceitação extremada de relações de dominação de caráter violento, material ou simbólico (Costa Pinto, 1997; Leeds, 1957) foram analisados como decorrência do patrimonialismo da sociedade brasileira. Coronelismo, mandonismo, patriarcalismo ou patrimonialismo fosse qual fosse a definição e as nuanças das formulações (Carvalho, 1999), o modelo de interpretação utilizado mostrava que a sociedade brasileira mantinha acesa a chama de uma forma de dominação, pessoalizada, arbitrária e hierárquica, em cujo sistema se processavam relações de troca recíproca até certo ponto bem-sucedidas, já que impediam a emancipação das camadas subordinadas e favoreceriam os donos do poder. O princípio da "maioridade" dos trabalhadores talvez encontre alguma afinidade com a interpretação que Maria Isaura Pereira de Queiroz faz do voto de cabresto em O Mandonismo local na vida política brasileira e outros ensaios (1976), mostrando que o voto de trabalhadores e pequenos proprietários rurais fazia parte de um sistema de troca recíproca com os políticos locais. Tratase, entretanto, de uma exceção.

Se até mesmo o "brasileiro" como um ser genérico fora tantas vezes visto como incapaz de ser moderno, e de internalizar os valores indispensáveis para uma conduta impessoal e igualitária, o que dizer dos menos letrados mergulhados no mundo da própria sobrevivência. Em grandes interpretações do Brasil, a exemplo de Carnavais, malandros e heróis de Roberto da Matta, a singularidade do problema brasileiro encontra-se, como afirma o autor, no "controle radical das mudanças". Tão autoritários quanto democráticos, os brasileiros não estariam aqui nem lá, mas simplesmente se habituaram a exercer controle sobre qualquer possibilidade de transformação efetiva da sociedade brasileira em uma sociedade moderna e igualitária. Antes mesmo de Roberto da Matta, Sérgio Buarque de Holanda discutia em Raizes do Brasil, de 1936, o controverso conceito de cordialidade brasileira, pondo em cheque a capacidade de os brasileiros se desvencilharem da prática de relações pessoais e autoritárias, que impedia a construção da sociedade moderna, atribuindo às origens ibéricas as causas de tal obstáculo.

Vale dizer que ao retomar intérpretes do Brasil como Oliveira Vianna, Gilberto Freyre ou Sérgio Buarque de Hollanda em O problema do sindicato único no Brasil, Evaristo de Moraes Filho o faz para avaliar suas contribuições específicas no que respeita à capacidade de associação livre por interesse sem ocupar-se de suas interpretações sobre a sociedade tradicional e a implantação de uma sociedade moderna (1978, pp. 308-319). Evaristo não somente se diferencia de seus antecessores como também de contemporâneos seus quanto ao tipo de "resposta" que poderia ser dada aos problemas do país. A resposta da intelectualidade brasileira tanto para o problema das associações livres por interesse no Brasil, como para tantos outros que evidenciavam para eles o "atraso" brasileiro, foi quase sempre mais pedagógica do que política. A educação traria consciência para a gente despossuída. Basta ver o projeto do CBPE (Centro Brasileiro de Pesquisas Educacionais), criado no Rio de Janeiro em 1955, sob inspiração de Anísio Teixeira, que contou com a participação ativa de Darcy Ribeiro e Costa Pinto. ${ }^{4}$ Ou verificar os registros do Seminário sobre Resistências à Mudança (1960), que Costa Pinto organizou no Rio de Janeiro em 1959, chamando a atenção para as adversidades econômicas e sociais com as quais tinham de contar aqueles que estavam engajados no desenvolvimento do país, e o papel que a educação poderia desempenhar no sentido de superar os obstáculos. 
Nada disso se assemelha ao livro de Evaristo. A solução que apresenta para o exercício da cidadania é de caráter associativo político e não de cunho pedagógico. Mudança de mentalidade haveria de ocorrer entre juristas, políticos e legisladores e não na classe trabalhadora. É preciso porém explicitar melhor os fundamentos de sua tese, comparando-a com o quadro conceitual das pesquisas da época, para compreender a posição do autor. O debate intelectual dos anos de 1950, meio ao qual o problema do sindicato único no Brasil vem a público, está interessado na passagem de uma sociedade tradicional para uma sociedade moderna. Grande parte dos cientistas sociais, considerando a existência de um padrão de desenvolvimento com base nas mudanças sociais ocorridas em sociedades como a inglesa, a francesa e a norte-americana, conclui que o processo de transição de uma ordem tradicional para uma ordem moderna no Brasil é problemático, elaborando concepções críticas daquele processo como se verifica no conceito de marginalidade estrutural de Costa Pinto (1960) ou na idéia de modernização reflexa de Darcy Ribeiro (1980). Podese ainda observar essa vertente crítica da história da modernidade no Brasil em um conjunto destacado de pesquisas que fizeram uso das idéias de desenvolvimento e atraso brasileiros (Vianna, 1999). O livro de Evaristo de Moraes Filho permaneceu fora desta influente vertente que emerge nos anos de 1950 para analisar o processo de mudanças no país a partir dos pares conceituais atraso/desenvolvimento e desenvolvimento/subdesenvolvimento. Justamente porque não fez uso da moldura que envolveu a maior parte dos estudos sociológicos, fundamentados em uma concepção de história processual que impunha um padrão único para a modernidade e, conseqüentemente, levava à representação da sociedade brasileira como ambígua e atrasada, Evaristo pode evidenciar a maioridade da classe trabalhadora no seu empenho associativo e reivindicatório.

A pergunta que se segue é, naturalmente, como foi possível a Evaristo remar contra a corrente de seu tempo, diferenciando-se de seus contemporâneos no que respeita ao reconhecimento da capacidade plena dos trabalhadores de exercerem a cidadania, lutando pelos seus direitos a me- lhores salários e condições de trabalho? O que o motiva a retirar a classe trabalhadora de sua minoridade, atribuindo-lhe a capacidade de associar-se livremente a favor de seus interesses? Há pelo menos duas modalidades de resposta a essas perguntas. Uma delas utiliza-se da própria memória do autor, o qual por diversas vezes, em depoimentos e entrevistas, especialmente as concedidas em 2002 por ocasião do cinqüentenário da publicação de $O$ problema do sindicato único no Brasil, reafirma o que escreveu no posfácio da edição de 1978, ressaltando que os oito anos de trabalho nas Comissões Mistas de Conciliação do recém criado Ministério do Trabalho foram decisivos para a elaboração do livro. A par disto, a influência exercida pelo seu pai Evaristo de Moraes, jurista "lutador social da República Velha", fizeram-no recusar a propalada idéia de que a legislação social havia sido uma outorga espontânea de Getúlio Vargas, considerando-se o movimento de 1930 como um divisor de águas relativamente às lutas operárias.

Antes mesmo de concluir o curso de direito em 1937, Evaristo ingressara na vida pública, no Ministério do Trabalho, como secretário das Comissões Mistas de Conciliação, no Rio de Janeiro, que haviam sido criadas em $1932 \mathrm{com}$ a finalidade de realizar acordos entre empregadores e empregados, cada parte designando três representantes. Não tinham competência judicante mas meramente conciliatórias, com funções de direito coletivo (greves, conflitos e convenções coletivas). O jovem secretariou essas Comissões até sua extinção, em 1941, quando foi criada a Justiça do Trabalho. Durante todo esse período, portanto, teve contato com ações trabalhistas e pôde acompanhar de perto a atuação dos sindicatos, tanto de empregados como de empregadores.

Em 1950, começa a dar aulas na Faculdade Nacional de Direito e inicia a elaboração de O problema do sindicato único no Brasil. A idéia original era apresentá-lo como tese de livre-docência na Faculdade Nacional de Direito. Mas Edgardo de Castro Rebelo, seu antigo professor da Faculdade de Direito, o dissuade da idéia. Evaristo fazia duras críticas à política trabalhista de Getúlio Vargas, com o intuito de desmistificar o mito estadonovista, o paternalismo, a outorga de leis trabalhistas. As pesqui- 
sas feitas sobre o sindicalismo resultaram no livro de 1952, enquanto a livre-docência em Direito viria em 1953, com a tese A justa causa na rescisão do contrato de trabalho.

Não desejo aqui, contudo, explicar a elaboração de O problema do sindicato único no Brasil como uma decorrência da biografia de seu autor, mas, antes, compreender como Evaristo de Moraes Filho reelaborou no plano das idéias acontecimentos que cunharam sua vida e experiências no contexto dos anos de 1930 e 1940. Se isto for possível, a segunda modalidade de resposta à pergunta de como pode Evaristo distinguir-se de uma geração de sociólogos e estudiosos, ao apostar na maioridade dos trabalhadores, encontra-se no plano das idéias que conformam a construção do argumento central de O problema do sindicato único no Brasil. O livro estrutura-se no princípio sociológico de que as práticas sociais antecedem a formalização das leis, modalidade compreensiva da vida social que vamos tratar a seguir.

\section{Sociologia versus direito}

O livro em questão é mais do que uma simples peleja contra os juristas que crêem no mito da outorga das leis trabalhistas por Getúlio Vargas, porém, uma tomada de posição contra a tese defendida no campo do direito, segundo a qual o corpo doutrinário e o caráter normativo das leis têm existência autônoma e própria. Herdeiros de uma tradição bem mais antiga do que a sociologia, os juristas nem sempre viram com bons olhos a ingerência da "nova" disciplina como meio explicativo e compreensivo do fato jurídico. Habituados à formulação de doutrinas e à construção dogmático-normativa, e munidos de vasto material experimental e teórico, os juristas desenvolveram sua prática na ciência do direito a partir de modelos lógicos e predeterminados aos quais ajustam soluções ou providências (Miranda Rosa, 1996). A manutenção da unidade interna do sistema jurídico torna-se conseqüentemente um de seus maiores objetivos:

O teórico do Direito procura obter o grau mais alto de coerência interna com um mínimo de mu- dança no seu sistema conceitual, de modo a contribuir para a manutenção da máxima segurança jurídica ou seja da possibilidade de prever a aplicação de normas e princípios jurídicos nos casos particulares. Dessa maneira é criada uma impressão de que o núcleo do Direito é constituído em grande parte de princípios permanentes, incidindo as transformações principalmente sobre aspectos periféricos ou secundários da ordem jurídica ou, então, operando as mudanças mais importantes segundo modos preestabelecidos e gradualmente, sem afetar a unidade interna do sistema (Idem, p. 46).

Ora, esse procedimento típico da prática legislativa torna compreensível a hostilidade e a recusa em aceitar os fundamentos sociológicos dos fatos e das leis. Porém, o princípio da coerência e da ausência de contradição entre as leis, que define procedimentos técnicos da prática legislativa, voltada exclusivamente para a manutenção da unidade do sistema de normas jurídicas, não explica por si a recusa da sociologia pelos juristas. Em 1950, dois anos antes, portanto, da publicação de O problema do sindicato único no Brasil, Evaristo lançou um dos raros livros sobre as relações entre a sociologia e o direito, na época, intitulado O problema de uma sociologia do direito. Escrevera para contestar seu professor e amigo Castro Rebelo, o qual não concebia qualquer relação entre essas duas disciplinas. Para Evaristo, a sociologia do direito era essencial para o esclarecimento de problemas ligados à eficácia do direito. Os legisladores precisam saber até que ponto uma norma jurídica efetivamente orienta a conduta dos homens ou se eles a neglicenciam e regem sua ação de acordo com outras normas e valores. ${ }^{5}$ De fato, a norma e o valor constituem matéria do direito, assim como a vigência e a validade da norma jurídica. Mas cabe à sociologia contribuir para a atividade doutrinária e normativa do direito com o conhecimento do fato social tal como ele ocorre com suas variações e interpretações diversas, não devendo limitar-se o entendimento dos fatos à sua definição pela norma jurídica. Como se vê, o positivismo da prática legislativa, tanto no que se refere à manutenção da coerência do sistema jurídico como no que respeita à coerência entre fato, valor e norma, encontra seus limites no conjunto 
das normas jurídicas, não admitindo nenhum conhecimento cuja origem se encontre fora do ordenamento jurídico. Esta concepção que não distingue a vida social do conjunto de normas dificilmente poderia acatar os pressupostos da sociologia.

O embate de Evaristo a favor do conhecimento sociológico ocorre significativamente no campo da ciência do direito. ${ }^{6}$ Quando formula o problema de uma sociologia do direito, no livro de 1950 , toma nada mais nada menos como adversário o jurista vienense Hans Kelsen, autor da teoria pura do direito. Compreende que a distinção entre validade e eficácia do direito, concebida por Kelsen, leva o autor a considerar que a validade das normas independe da obediência que se lhes presta, servindo elas apenas para provocar fatos. As normas simplesmente estabelecem um dever ser, caso contrário seriam uma lei natural, infalível e determinista. Suspendendo a obediência como prova da eficácia das normas, a concepção de Kelsen é vista por Evaristo como abstrata e estéril:

O objeto do estudo do jurista, como tal, se resume a deduzir uma norma da outra, desde a norma fundamental, num trabalho analítico de construção, de sistematização, de ordenação lógica dessas mesmas normas, como alguém que joga paciência com cartas. Concordamos que a norma, constituída de um juízo hipotético - se tal for feito ou deixar de sê-lo, tal pena será aplicada -, constitui um dever ser, que se interessa pela conduta futura dos homens; mas como se negar a importância da sua eficácia no momento e no meio para os quais foi promulgada, afinal de contas? (1997, p. 208).

Entende-se melhor agora o grande esforço de pesquisa de Evaristo de Moraes Filho - o levantamento e a consulta a diversas fontes teóricas e históricas, a leitura de autores nacionais e estrangeiros - que resultaram em O problema do sindicato único no Brasil, como se não quisesse deixar nenhuma lacuna por meio da qual seus adversários pudessem abrir um flanco e argumentar contra sua tese contrária ao mito da outorga das leis trabalhistas. Defendendo um ponto de vista distinto da maioria de seus colegas juristas, no que respeita às relações entre direito e sociologia, Evaristo pode insistir, em seu livro, no fato de que a existência de grupos sociais e sua capacidade de se associar livremente para lutar pelos seus interesses independem de seu reconhecimento no corpo da lei. Partindo de um princípio sociológico pragmático, afirma que as ações sociais que os indivíduos empreendem e as relações sociais que vão travando ao longo de suas vidas são o fundamento do mundo social. O homem não é um ser isolado, nem a humanidade uma entidade abstrata, mas a sociedade se constitui de indivíduos que se relacionam uns com os outros. As ciências sociais, cujo objetivo é o estudo dessa tessitura social, podem almejar a neutralidade valorativa ou definir-se por um sentido normativo como é o caso da ciência do direito. A fim de assegurar vigência e validade aos aspectos normativos a serem legislados sobre um determinado fenômeno, o direito deveria atuar juntamente com a sociologia, a economia e a história a fim de conhecer os fatos sociais sem interferência dos valores que subjazem às normas que regularizam juridicamente aqueles fatos.

No caso específico do estudo do sindicato, o direito antes de fazer uso de suas prerrogativas de caráter normativo deveria indagar pelo sindicato como um fato social que resulta da ação consciente e voluntária do homem. Afirma Evaristo que nem os políticos nem os legisladores devem se debruçar sobre o problema sindical sem antes consultar a sociologia e a economia, para delas obter um conceito imparcial, sob pena de tentar resolvê-lo de acordo com seus interesses, preconceitos, compromissos, crenças e ideais (1978, p. 8).

Em O problema do sindicato único no Brasil, o esclarecimento do que seja o conceito de grupo do ponto de vista sociológico não é somente o primeiro passo na seqüência dos capítulos do livro, mas o passo fundamental de uma estratégia que visa a convencer os leitores da importância da sociologia para a prática legislativa. A compreensão do que significa política e socialmente uma associação de indivíduos é pressuposto do entendimento do papel dos movimentos operários na formulação da legislação trabalhista. No seu empenho em defesa da sociologia, Evaristo de Moraes Filho afirmava que a disciplina havia mudado e, como resultado da mudança de cri- 
térios metodológicos, a sociologia se desvencilhara do conceito genérico de sociedade, que englobava toda a humanidade, e adotara o conceito de grupo social mais adequado para a pesquisa (Idem, p. 19).

Ao discutir o conceito de grupo social, Evaristo retoma diferentes formulações de autoria de sociólogos franceses, alemães e norte-americanos, evidenciando sua familiaridade com uma longa e exaustiva bibliografia. Se compararmos os sociólogos, representantes de diferentes vertentes da disciplina, que integram a discussão conceitual em O problema do sindicato único no Brasil, com os autores constantes da bibliografia, indispensável para a formação do sociólogo, indicada por Florestan Fernandes, em 1959, em seu Sociologia geral e aplicada (1976), nota-se o quanto as escolhas dos dois se aproximam. No entanto, embora se possa imaginar um mesmo quadro de referências para os dois sociólogos, o propósito de Evaristo de Moraes Filho em introduzir uma nova abordagem das organizações sindicais do ponto de vista sociológico o faz se posicionar a favor da associação dos agentes humanos que, ao longo de sua prática cotidiana e histórica, criam valores, instituições e mentalidade, recriando ele no seu trabalho uma teoria da ação social, cujos componentes se encontram nos fundamentos de uma vertente pragmática da sociologia alemã e norteamericana. Sua escolha o distingue, pois, dos sociólogos dos anos de 1950, que aderiram a um princípio totalizador e explicativo da vida em sociedade. Evaristo pretende, antes, pôr em evidência o fragmento de uma relação conflituosa entre trabalhadores e o Estado, retirando daí todas as conseqüências sociológicas.

Em Oproblema do sindicato único no Brasil, a escolha do conceito de grupo social exclui a noção de classe social, seja na sua versão marxista voltada para a inserção de grupos sociais no processo produtivo, que define uma totalidade histórica e social, seja na versão weberiana de aquisição e partilha de bens materiais e espirituais na sociedade ocidental capitalista. A produção sociológica brasileira dos anos de 1950 foi muitas vezes nomeada de classista, subtendendo-se com este termo sobretudo a utilização do conceito de classe social na sua acepção marxista. Não se pode aqui fazer uma revisão crítica dessa perspectiva interpretativa do pensamento sociológico, porém, evidenciar que, ao estudar a classe trabalhadora brasileira, Evaristo de Moraes Filho aborda suas ações concretas e não se ocupa em esquadrinhar a lógica das desigualdades sociais de grupos, classes ou indivíduos. Se o livro trata de uma partilha, esta partilha é a partilha de direitos. Os trabalhadores lutam pela aquisição de direitos.

A escolha teórico-conceitual de Evaristo de Moraes Filho contraria a crença na performance dos grandes homens, como seres isolados, capazes por sua inteligência e genialidade de grandes feitos históricos e políticos. Essa crença, tão comum ainda nos dias de hoje, é contestada pelo autor quando abre o debate sobre grupo e profissão, muito embora a teoria da genialidade dos "grandes homens" não constitua alvo específico de crítica do seu trabalho.? Não se pense que enveredou então pela busca de um "espírito de um povo" para justificar suas teses. Ao fundamentar sua argumentação no conceito de grupo, o autor assume o caráter fragmentário do conhecimento histórico e sociológico sem buscar apoio em qualquer princípio último totalizador. Não há uma ordem natural explicativa da vida social, como também não há uma crença no desenvolvimento histórico numa única direção. Aliás, O problema do sindicato único no Brasil, como diz o próprio autor, não é um ensaio de natureza histórica mas de ordem sistemática (1978, p. 182). Evaristo não adota tampouco uma concepção de história de caráter processual e, por isso, não vai às origens da sociedade brasileira para verificar os encadeamentos de um processo no decorrer do tempo, muito embora seu estudo se baseie em evidências históricas da participação organizada de trabalhadores e operários, desde finais do século XIX até os anos de 1930, em lutas pela melhoria de sua condição de vida. Desconfiando da imutabilidade da vida social e buscando comprovar a importância da ação dos grupos para as mudanças sociais e políticas, Evaristo guarda, entretanto, uma posição diferente de muitos de seus contemporâneos que se dedicavam às análises histórico-processuais, a exemplo do Formação do Brasil contemporâneo de Caio Prado Jr. (1942), ao mesmo tem- 
po em que se distancia de interpretações do Brasil como a de Sérgio Buarque de Holanda, em Raízes do Brasil (1936), que valorizava as origens da sociedade como entidade explicativa de uma sucessão de fatos posteriores.

A adoção de uma concepção de sociedade baseada na ação de grupos sociais, associada a uma concepção de história que não desqualifica o passado nem se atrela a um ideal futuro, permite a Evaristo argumentar que os grupos profissionais existem e precedem qualquer "tentativa de regulamentação de suas atividades pelo Direito" (Moraes Filho, 1978, p. 60), tanto no Brasil como em outros países. Eis uma das principais tarefas de Evaristo, cuja realização faz o autor mobilizar boa parte da sociologia.

A existência dos grupos de profissão na sociedade capitalista estimula o agrupamento de pessoas para lutar pela melhoria das condições de trabalho e da vida profissional. A organização dos sindicatos, porém, sempre foi considerada uma ameaça à soberania do Estado desde seu surgimento nos países europeus. Na França, as teses de Rousseau e o individualismo igualitarista da revolução francesa levou Le Chapelier a legislar a favor dos interesses individuais porém não comuns. Demorou muito para que as associações e os sindicatos fossem reconhecidos na organização pública dos Estados modernos porque, no momento em que o sindicato passa a existir como ente coletivo e duradouro, põe em xeque a soberania do Estado. Neste ponto, o autor diz chegar ao cerne do problema em foco, que consiste nas relações entre as associações sindicais e o Estado (Idem, p. 114).

Não é preciso ir muito longe para perceber que o argumento do autor incide no deslocamento do Estado do lugar privilegiado que ele assume como móvel de construção da sociedade. As regras do direito não fundam as instituições, ao contrário, são as instituições que fazem as regras do direito (1978, p. 95). Contudo, a perspectiva sociológica de Evaristo de Moraes Filho não repercute apenas na revisão da eficácia das normas jurídicas e seus efeitos sociais. Ao posicionar-se contra o mito da outorga das leis trabalhistas no Brasil e contrariar as teses da ciência do direito que reconhecem no Estado a única fonte do direito, apos- tando na ascendência do ordenamento jurídico no "fazer sociedade", questiona uma das mais bem consolidadas interpretações sobre o país, que diz respeito ao poder (quase único e absoluto) do Estado na construção da nação e da sociedade. Hoje, no início do século XXI, tal posição pode ser compreendida ou tolerada, mas imagine-se o que significou no Brasil, no início dos anos de 1950, quando o Estado era visto como verdadeiro portador da modernidade brasileira ou, ainda, em outra acepção, como responsável pela expansão autoritária do capitalismo na periferia. Imagine-se esta posição da década de 1950 quando a visão hegemônica dos estudiosos e intelectuais atribuíam ao Estado tal missão "civilizatória". Compreende-se mais uma vez por que o livro de Evaristo de Moraes Filho teve sua recepção tardia.

Contudo, seria um equívoco pensar que, ao se posicionar contra o mito da outorga, atribuindo maioridade aos trabalhadores e restringindo, com sua argumentação, o poder e a força do Estado, Evaristo desconsidere o papel do Estado. O que advoga é a mudança na concepção do papel do Estado. A lei é o fundamento da autoridade legítima do Estado, e para que possa legislar de acordo com as especificidades da sociedade moderna é preciso que se acabe com a crença na infalibilidade e soberania única do Estado. Tal prepotência perde sua razão de ser nos tempos modernos. O autor reconhece no Estado uma associação cuja função é regularizar e harmonizar os interesses de outras associações. O Estado é ele próprio uma associação, "uma organização de serviço público”, cujo objetivo precípuo é prover os cidadãos de serviços que não podem sustentar nem produzir por si mesmos (1978, p. 127). Mais uma vez a sociologia, especificamente o conceito de grupo social atua a seu favor. A vida social, argumenta Evaristo, não é um conjunto de indivíduos isolados, separados e amorfos, mas uma rede complexa de "corpos sociais" - famílias, sindicatos, igrejas, partidos políticos, colégios, profissões, clubes. A soberania interna do Estado é mais complexa do que a externa, pois concerne a um "choque de representações". É evidente que o Estado é uma associação única em sua espécie no que respeita à sua autoridade, controle, territoria- 
lidade e coação, porém, é preciso identificá-lo a outras associações para que se acabe com a mística de sua soberania e se faça reconhecer o seu novo lugar. Evaristo de Moraes Filho parte do princípio de que a estrutura íntima do Estado contemporâneo se modificou no contato com as novas formas de organização coletiva. Por isso reivindica a modernidade para o Estado legislador que nada tem a ver com a criação de postos e cargos e especialização de seus funcionários ou com o alargamento de seus setores burocráticos e exigência de competências específicas para seus integrantes, tampouco com a condução da política econômica. A modernização do Estado, caso possamos assim chamá-la, pois que não se trata de expressão utilizada pelo autor, diz respeito à capacidade legislativa do Estado na regularização e no controle racional de uma diversidade de interesses advindos de agrupamentos e associações.

Insistindo no caráter coletivo/plural/associativo em oposição ao caráter individual e único da vida social, Evaristo afirma que o problema do legislador é encarar o grupo como sujeito jurídico e não o indivíduo isolado. Para tanto é preciso que mude sua mentalidade. Eis o problema. O verdadeiro liberalismo da época do pós-guerra é aquele que, sem privar os indivíduos de sua liberdade, possa contemplá-la sem perda de vantagens para a coletividade. Evaristo reconcilia-se, enfim, com sua contemporaneidade. Relembrando a tese sobre planificação e liberdade de Karl Mannheim, ${ }^{8}$ ele se põe contra o Estado autoritário e de soberania ilimitado, e, ao mesmo tempo, contra o Estado do liberalismo individualista da revolução francesa. Coerente, retoma a idéia de grupo, agora para argumentar que o grupo sindical representa a vontade coletiva. E não apenas isto. Os conflitos não se restringem aos grupos em contenda, mas interessam a muitos outros indivíduos e grupos que formam a sociedade e cujas vidas serão afetadas com o desfecho daquelas lutas:

É tão evidente o imenso interesse público que se prende aos dissídios coletivos de trabalho, quase sempre restritos à fixação de salários profissionais ou a aumentos de salários, para que percamos tempo com esta matéria. Não estão em jogo exclusivamente as forças patronais e operárias em contenda, toda a sociedade assiste ao desenrolar da luta e espera o resultado final. Todas as classes sociais têm interesses envolvidos em tais questões e espiam de longe como a conduzem. Do preço da mão-de-obra, num verdadeiro sistema fechado de concausas, irão depender os outros preços das utilidades, todo o mercado será afetado, com correspondente modificação do custo de vida. [...] a solução arbitral ou jurisdicional do conflito de trabalho pode alterar sensivelmente as regras ordinárias na formação de preços. E nem sempre são levadas em conta exclusivamente razões de ordem econômica, podendo predominar neste ou naquele caso, segundo as forças dos grupos em luta, razões outras de ordem política ou social (Moraes Filho, 1978, p. 161).

Mais uma vez fica esclarecida a posição do autor de que não é preciso explicar a sociedade por um princípio totalizante para se dar conta da interdependência que conforma as ações dos grupos e dos indivíduos na sociedade. As lutas das associações sindicais afetam o conjunto da sociedade e impõem uma nova concepção para a prática legislativa. Por isso, Evaristo propõe um longo debate sobre o caráter individualista da legislação e o caráter coletivo das leis, revisitando o individualismo igualitário oriundo do universalismo da revolução francesa e, por conseguinte, o ideário do liberalismo político, com vistas a assegurar a manutenção da soberania e da autoridade do Estado juntamente com existência dos sindicatos e associações. A tarefa da democracia no pós-guerra, afirma o sociólogo e jurista, é reunir liberdade individual com autoridade e, dessa forma, distanciar-se do individualismo tradicional da revolução francesa, retendo o que tem de positivo, porém abandonando sem pena o que nele não esteja mais adequado aos novos tempos (Idem, p. 173).

Recapitulemos os passos da argumentação do autor, no que concerne ao seu embate no campo da ciência do direito pela intromissão da sociologia, pois isso é importante para responder à pergunta inicial sobre como foi possível a Evaristo de Moraes Filho defender a maioridade dos trabalhadores brasileiros. O problema do sindicato único no Brasil fundamenta-se em arcabouço sociológico, no qual as noções de associação, interesse e ação coletiva são indispensáveis para que o autor 
se contraponha aos princípios mais convencionais e formais da prática legislativa. Uma vez que a sociedade se configura com uma multiplicidade de ações e relações conflituosas ou não, advindas de interesses de grupos diversos, tal configuração impõe ao Estado uma renovação de seu papel, sua autoridade e soberania, voltados agora para o equilibrio de interesses de grupos diversos.

\section{O caráter nacional brasileiro em O problema do sindicato único no Brasil}

À época de elaboração e publicação do livro em pauta, a peleja que Evaristo liderava no campo da ciência do direito não se limitava à defesa da introdução de uma visão sociológica dos fatos na prática legislativa. Ele combatia também as teses sobre o caráter nacional que atestavam a incapacidade de o povo lutar pelos seus direitos. Nesse sentido, Oliveira Vianna foi certamente seu grande interlocutor, podendo-se considerar O problema do sindicato único no Brasil um libelo não só contra a outorga das leis trabalhistas pelo regime autoritário de Vargas, mas também contra as teses do insolidarismo social brasileiro, propugnadas pelo sociólogo fluminense, consultor jurídico do Ministério do Trabalho de 1932 a 1940. O embate de Evaristo dava-se, pois, em várias frentes. Usava a sociologia tanto para se opor às concepções exclusivamente doutrinárias e normativas dos juristas sobre os fatos sociais, como para desmistificar as concepções sobre o caráter faltoso do "povo" brasileiro. Nessa "frente de luta", entretanto, o embate se dava de forma mais velada, menos clara e explícita.

As idéias de Evaristo atingiam juristas e intelectuais que, partindo como ele próprio de um princípio sociológico, concluíam, no entanto, pela incapacidade de a classe trabalhadora lutar pelos seus interesses, entre outros motivos, devido ao seu passado escravista, predominância da produção agrícola e do latifúndio na história do país. Com base nessa premissa, seus adversários julgavam que o Estado deveria tomar as rédeas da organização dos trabalhadores. O mito da minoridade tinha raízes profundas já naquela época. No direito, Antonio Ferreira Cesarino Jr. escrevera vários livros em que defendia a tese de que cabia ao Estado a tarefa da organização das associações de trabalhadores. ${ }^{2}$ Em Direito social, publicado em 1940, Cesarino Jr. admitia que, no Brasil, a predominância do trabalho agrícola e servil fora responsável pelo que chamava de "inversão sindical brasileira", definindo com aquela expressão a diferença entre a história sindical brasileira e a européia. Enquanto na Europa, os trabalhadores lutaram para formar livremente suas associações profissionais e de classe, no Brasil, a organização sindical foi concebida pelo Estado (Cesarino Jr., 1980, p. 511).

O leitor habituado com a conhecida idéia do atraso e da incapacidade do brasileiro surpreendese com o rol das lutas operárias e dos movimentos dos trabalhadores, estampados em O problema do sindicato único no Brasil. Ao descortinar o conjunto de greves e movimentos da classe trabalhadora no início do século passado, Evaristo relaciona aquelas ações ao trabalho de juristas, a exemplo de Evaristo de Moraes, Maurício de Lacerda e Joaquim Pimenta, que lutaram pela regulamentação das leis trabalhistas. O cuidado em evidenciar a relação entre os grupos em luta e os legisladores tinha o objetivo de mostrar que as lutas dos trabalhadores haviam precedido às leis, um dos pontos importantes da argumentação do autor, e, por conseguinte, que os trabalhadores tinham capacidade associativa. As noções de atraso, modernidade, desenvolvimento estavam absolutamente fora do esquema conceitual do autor, mas não se pode deixar de aproximar a posição assumida por Evaristo, e relativa à capacidade associativa dos trabalhadores, à constituição de uma sociedade moderna. Ao expor os conceitos fundamentais de sua sociologia compreensiva, Max Weber define a relação associativa quando homens e mulheres agem no sentido de

[...] um ajuste ou uma união de interesses racionalmente motivados com relação a valores e fins. Um acordo racional [...] a união livremente pactuada e puramente orientada por determinados fins: um acordo sobre uma ação contínua, destinado em seus meios e propósitos exclusivamente à persecução de interesses econômico ou outros dos participantes (Weber, 1991 p. 25). 
Essa relação associativa, como um acordo racional, está relacionada à construção ideal típica das sociedades de cultura ocidental capitalista. Ao demonstrar a capacidade associativa dos operários brasileiros, atribuindo-lhes a maioridade para lutar por seus direitos, Evaristo não trata de outra problemática senão a da construção de uma sociedade moderna.

Nas últimas páginas de O problema do sindicato único no Brasil, o autor retoma as interpretações do Brasil que reclamam da falta de "espírito associativo" dos brasileiros. Não as retoma para contrariá-las, como se poderia supor, mas para reafirmar sua validade e evidenciar, por meio das teses sobre o insolidarismo brasileiro, o quanto se deveria lutar a favor do agrupamento dos indivíduos por interesse. A argumentação servia acima de tudo para fundamentar a idéia de um sindicato único por profissão, que Evaristo defendia. Quanto menos fragmentação houvesse nas associações, maior força teriam os sindicatos em um país onde os laços por interesse eram tão enfraquecidos. $\mathrm{Na}$ realidade, a evocação das teses sobre o insolidarismo social, como verdadeiro contraponto, deixa ainda mais claro o quanto o livro se ergue como um monumento contra a idéia de um caráter brasileiro inconsistente e inapto para as tarefas associativas e para o exercício da cidadania, no que concernia às lutas operárias. Se existia tal insolidarismo, não era, contudo, uma marca indelével dos brasileiros. Além do que, tomá-lo como ponto de partida significava correr o risco de concluir pela imperiosa necessidade de um regime político autoritário.

Anos mais tarde, em um elucidativo ensaio sobre Oliveira Vianna, sob o título "Oliveira Vianna e o direito do trabalho no Brasil" (Moraes Filho, s/d), explicita-se a oposição de Evaristo em relação às conseqüências práticas daquelas teses a concentração da capacidade decisória no poder executivo, como propugnava Oliveira Vianna. Desfiando ponto por ponto do pensamento conservador e autoritário do sociólogo de Saquarema, Evaristo distingue na ação e na obra do jurista a defesa do direito individual e particular, com base no princípio da eqüidade, ainda que Oliveira Vianna pregasse contra a livre manifestação de associações e sindicatos, fundada no direito coletivo: "liberal, bem liberal, assumindo um papel inovador no direito individual do trabalho, o mesmo não poderia ser dito quanto ao direito coletivo" (Idem, p. 88). Mas, apesar das distinções indispensáveis e esclarecedoras do pensamento de Oliveira Vianna, Evaristo não se deixa seduzir pela sua interpretação do caráter brasileiro e conseqüente visão instrumental de um Estado forte. Em "Uma possível nota do caráter nacional", de 1971, volta ao tema e ao que havia afirmado sobre ele no livro de 1952. A noção de caráter nacional ou brasileiro é vaga e inconsistente. Podese até mesmo reconhecer uma psicologia dos povos, que se define por traços culturais comuns e constantes em certos grupos. O que não se pode admitir é o exagero, a plasticidade e a volubilidade daquelas definições de caráter nacional, e, sobretudo, o que não se pode admitir é que o caráter de um povo não se transforme ao longo do tempo.

Em O problema do sindicato único no Brasil, Evaristo de Moraes Filho reelaborou a experiência marcante das lutas sociais, as quais conhecera por intermédio da trajetória de seu pai, Evaristo de Moraes, e presenciara quando jovem secretário das Comissões Mistas de Conciliação no Ministério do Trabalho. Posicionou-se contra as teses formalistas sobre a prática legislativa da teoria do direito; e contra as teses sobre o insolidarismo do caráter nacional ou ethos brasileiro. A elas opôs uma teoria sociológica pragmática, em que associação, interesse e ação são elementos fundamentais. Esse arranjo de idéias cunha seus argumentos voltados para a desmistificação do mito da outorga das leis trabalhistas. Retirando o Estado de seu lugar de portador de toda ordem, modernidade e progresso, e delegando aos sujeitos sociais a capacidade de lutar pelos seus interesses, Evaristo de Moraes Filho devolve aos trabalhadores brasileiros a sua maioridade.

\section{NOTAS}

1 O Decreto n. 1.9770/1931 regula a sindicalização e o Decreto 21396/1932 proíbe a greve. Em 1939, uma nova legislação sindical regula 
a intervenção ministerial no sindicato (Moraes Filho, 1979).

2 O desenvolvimento dos estudos sociológicos sobre o sindicalismo, nas três primeiras décadas após da publicação do livro de Evaristo de Moraes Filho, pode ser visto em Azis Simão (1971), Martins Rodrigues (1971) e Werneck Vianna (1978, 1984).

3 Tomo de empréstimo os termos minoridade e maioridade de Kant sem nenhuma intenção de retomá-los no sentido estrito das teses do filósofo em Resposta à pergunta: que é "esclarecimento"? (Kant, 1985).

4 Florestan Fernandes e Gilberto Freyre, entre outros, também participaram do projeto (Dias da Silva, 2002). Sobre a criação do CBPE, ver Centro Brasileiro de Pesquisas Educacionais (Documentos iniciais), Educação e Ciências Sociais, 1 (1), ano 1, 1956.

5 Entrevista de Evaristo de Moraes Filho a sua filha Regina Lucia de Moraes Morel, em 2002. Agradeço à Regina Morel a gentileza de me ter cedido este e outros materiais para a confecção deste artigo.

6 Nesse sentido vale distinguir uma outra modalidade de institucionalização da sociologia, a que ocorre no campo do direito e se difere da modalidade mais conhecida, que se dá nos campos da história política, da antropologia e do folclore.

7 Ao discutir as relações entre o movimento de trabalhadores e a legislação trabalhista afirma o autor: "[...] já vinha amadurecendo a legislação social, como provamos através de algumas páginas anteriores, nos movimentos operários, nos congressos dos trabalhadores, nas mensagens do Executivo, nos trabalhos legislativos, na doutrina jurídica, nas plataformas políticas, enfim na própria consciência da nação. A revolução nunca é obra de um homem só, por mais genial que seja. Não houve saltos na continuidade histórica. A moderna concepção de estudos históricos abandonou o critério antiquado da história oficial e heróica, em que somente aparecem em cenário, dignos de pousar para posteridade, os figurões de primeira fila. O que mantém o espetáculo é justamente o coro meio anônimo, são figuras de segundo plano, mais numerosas mais constantes [...]" (1978, p. 218).

8 Sobre a recepção de K. Mannheim pelos sociólogos brasileiros, ver Villas Bôas (2002).

9 Antonio Ferreira Cesarino Jr. era professor catedrático das faculdades de Direito e Economia da Universidade Estadual de São Paulo. Escreveu diversos livros entre os quais Direito corporativo e direito do trabalho (1940), Direito social brasileiro (1940) e Direito processual do trabalbo (1942). Em O problema do sindicato único no Brasil, Evaristo refere-se uma vez ao autor quando discute problemas da representação sindical na Constituição de 1937 (1978, pp. 248-249), contudo, na entrevista concedida em 2002, relembra-se de Cesarino Jr. como um dos adversários das teses de seu livro.

\section{BIBLIOGRAFIA}

ARENDT, Hannah. (1988), On revolution. Nova York, Peguin Books.

BUARQUE DE HOLANDA, Sérgio. (1995), Raízes do Brasil. 4 ed., São Paulo, Companhia das Letras.

CARVALHO, José Murilo.(1999), "Mandonismo, coronelismo, clientelismo: uma discussão conceitual”, in Pontos e bordados: escritos de bistória e política., Belo Horizonte, Editora da UFMG.

CESARINO Jr., Antonio Ferreira. (1980), Direito social. 6 ed., São Paulo, LTR/Edusp.

COSTA PINTO, Luiz de Aguiar. (1960), "Resistências à mudança: fatores que impedem ou dificultam o desenvolvimento". Centro Latino-Americano de Pesquisa em Ciências Sociais, 10, Rio de Janeiro.

(1997), Recôncavo: laboratório de uma experiência humana. 2 ed., Salvador, Editora Costa Pinto. 
DIAS DA SILVA, Graziella Moraes. (2002), Sociologia da sociologia da educação: caminhos e desafios de uma policy science no Brasil (1920/1979). Bragança Paulista, Edusf.

FERNANDES, Florestan. (1976), Ensaios de sociologia geral e aplicada. São Paulo, Livraria Pioneira Editora.

KANT, Immanuel. (1985), Textos seletos. Petrópolis, Vozes.

LEAL, Vitor Nunes. (1948), Coronelismo, enxada e voto. Rio de Janeiro, Forense.

LEEDS, Anthony. (1957), Economic cycles in Brazil: the persistence of a total cultural pattern (Cacao and other cases). Dissertação apresentada na University of Columbia, Nova York.

MARTINS RODRIGUES, Leôncio. (1971), "Bibliografia sobre o sindicalismo e os trabalhadores industriais no Brasil: notas para um esquema explicativo". Introdução ao Estudo da Sociologia no Brasil, Caderno 2, IEB, USP, pp.157-183.

MIRANDA ROSA, F. A de. (1996), Sociologia do direito: o fenômeno jurídico como fato social. 13 ed., Rio de Janeiro, Jorge Zahar Editor.

MORAES FILHO, Evaristo. (s/d), "Oliveira Vianna e o direito do trabalho no Brasil". LTrJornal do Congresso, pp. 77-90.

. (1978), O problema do sindicato único no Brasil: seus fundamentos sociológicos. 2 ed., São Paulo, Alfa-Omega.

. (1971), "Uma possível nota do caráter brasileiro". Carta Mensal, 196: 3-15, ano XVI, Rio de Janeiro.

. (1979) "Uma legislação que sobrevive aos regimes". Isto E, 4 abr., pp. 64-65.

(1997), O problema de uma sociologia do direito. 2 ed., Rio de Janeiro, Renovar.

PEREIRA DE QUEIROZ, Maria Isaura. (1976), O mandonismo local na vida política bra- sileira e outros ensaios. São Paulo, Alfa Omega.

PRADO JR., Caio. (1961), Formação do Brasil contemporâneo, São Paulo, Brasiliense.

RIBEIRO, Darcy. (1980), Teoria do Brasil. 5 ed., Petrópolis, Vozes.

SIMÃO, Aziz. (1971), "Informação sobre o sindicalismo e a sociologia do sindicato no Brasil". Introdução ao Estudo da Sociologia no Brasil, Caderno 2, IEB, USP, pp. $147-156$.

VIANNA, L. Werneck. (1978), "Estudos sobre sindicalismo e movimento operário: resenha de algumas tendências". BIB, 3: 9-24.

(1984), "Novo sindicalismo', cidadania e fábrica". $B I B, 17:$ 53-68.

(1999), "Weber e a interpretação do Brasil", in Jessé Souza (org.), O malandro e o protestante: a tese weberiana e a singularidade cultural brasileira, Brasília, Editora da UnB, pp. 173-193

VILLAS BÔAS, Gláucia. (2002), "Os Portadores da síntese: sobre a recepção de Karl Mannheim". Cadernos do CERU, 13 (2): 125141.

WEBER, Max. (1991), Economia e sociedade. Brasília, Editora da UnB.

WILLEMS, Emílio. (1952), Buzios Island: a caiçara community in Southern Brazil. Nova York, J. J. Augustin Publisher. 
REVISTA BRASILEIRA DE CIÊNCIAS SOCIAIS - VOL. 19 No. 55

\section{EVARISTO DE MORAES FILHO E A MAIORIDADE DOS TRABALHA- DORES BRASILEIROS}

Glaucia Villas Bôas

\section{Palavras-chave}

Modernidade e associação por interesse; Sociologia e Direito; Insolidarismo; Caráter nacional.

Ao relembrar os cinqüenta anos de edição de O Problema do sindicato único no Brasil: seus fundamentos sociológicos (1952), de Evaristo de Moraes Filho, o artigo retoma sua leitura, ressaltando que, diferentemente de contemporâneos seus, o autor recusa as hipóteses de uma cultura da incapacidade dos brasileiros, atribuindo aos trabalhadores maioridade para lutar pelos seus direitos. Com o objetivo de evidenciar o papel de importância das lutas operárias na constituição das leis trabalhistas, Evaristo de Moraes Filho faz uso de instrumental sociológico, opondo-se tanto às concepções normativo-doutrinárias dos juristas como às teses sobre o insolidarismo formuladas por cientistas sociais brasileiros. Argumenta-se que a posição do sociólogo e jurista quanto à positividade das associações sindicais resulta da moldura teórica e conceitual adotada, que exclui as noções de atraso e subdesenvolvimento.

\section{EVARISTO DE MORAES FILHO AND THE COMING OF AGE OF BRAZILIAN WORKERS}

Glaucia Villas Bôas

\section{Key words}

Modernity and association through interest; Sociology and the law; Lack of solidarity; National character.

While recalling the 50 years since the publication of "The Single Union Issue in Brazil. Its Sociological Foundations" (1952), by Evaristo de Moraes Filho, the article takes up its reading again, stressing that the author, unlikely his counterparts, rejects the hypothesis of a theory of Brazilian incapacity, endowing workers with majority to fight for their rights. For the purpose of bringing into evidence the important role of workmen's struggles in the making up of labor laws, Evaristo de Moraes Filho makes use of sociological tools in opposition both to jurists' normative-doctrinaire concepts and to theories supporting lack of solidarity, as formulated by Brazilian political scientists. The position of sociologists and jurists about the positiveness of union associations is a result of the theoretical and conceptual framing used, which excludes backwardness and underdevelopment notions.

\section{EVARISTO DE MORAES FILHO ET LA MAJORITÉ DES TRAVAILLEURS BRÉSILIENS}

Glaucia Villas Bôas

Modernité et association par intérêt; Sociologie et Droit; Manque de solidarité ; Caractère national.

Cet article propose une relecture du livre d'Evaristo de Moraes Filho, publié il y a 50 ans, intitulé "Le problème du syndicat unique au Brésil: ses fondements sociologiques" (1952). Contrairement à ses contemporains, l'auteur refuse les hypothèses d'une théorie de l'incapacité des brésiliens, en attribuant aux travailleurs leur majorité pour se battre pour leurs droits. Pour mettre en évidence le rôle important des luttes ouvrières dans la constitution des lois du travail, Evaristo de Moraes Filho se sert des outils sociologiques, en opposant à la fois les conceptions normative-doctrinaires des juristes et les thèses sur le manque de solidarité, formulées par les scientistes politiques brésiliens. Nous soutenons que la position du sociologue et du juriste à l'égard de la positivité des associations syndicales, résulte de l'encadrement théorique et conceptuel adopté, qui exclut les notions de retard et de sous-développement. 